\title{
A Study on the Prevalence of Chlamydia Trachomatis and Neisseria Gonorrhoeae Infections Using Polymerase Chain Reaction
}

\author{
Dr. S. Kalaivani., M.D., D.V \\ Associate Professor of STD, Institute of Venereology, Madras Medical College, Chennai -600003, Tamil Nadu, India
}

\begin{abstract}
Introduction: The Amplicor Chlamydia trachomatis / Neisseria gonorrhoeae (CT /NG) test is a qualitative in vitro test for the detection of Chlamydia trachomatis and Gonococcal infection. Aims and Objectives: To study the prevalence of Chlamydia trachomatis and Neisseria gonorrhoeae infections, in 280 males and 270 Non-Pregnant females who has not taken antibiotics four weeks prior to examination attending the OPD of Institute of Venereology, from March 1,2007 to February 29, 2008. Results: 14.64\% of males and $13.34 \%$ of females were positive for gonococcal infection. $3.57 \%$ of males and $3.70 \%$ of females were positive for Chlamydial infections. Burning micturition was common in males (NG-53.65\%, CT-80\%). In females genital discharge was common (NG-50\%, CT-50\%) Conclusion: Urine specimens (M-16, F-15) was highly sensitive) in detecting gonococcal infections. In Chlamydial infections of males urine PCR was highly sensitive but in females, endocervical swab PCR was more sensitive .
\end{abstract}

Keywords: Neisseria Gonorrhoea(NG),Chlamydial Infection(CT), Polymerase Chain Reacton (PCR), Endocervical Swab, Urethral Discharge

\section{Introduction}

Chlamydia trachomatis and Neisseria gonorrhoeae remain the two most preventable causes of human infertility ${ }^{1,2}$. The Amplicor Chlamydia trachomatis / Neisseria gonorrhoeae (CT /NG) test is a qualitative in vitro test for the detection of Chlamydia trachomatis and Neisseria gonorrhoeae in urine from both sexes, in endocervical swab specimens from females and in urethral swab specimens from males.

\section{Aims and Objectives}

To study the prevalence of Chlamydia trachomatis and Neisseria gonorrhoeae infections, in 280 males and 270 Non-Pregnant females who has not taken antibiotics four weeks prior to examination attending the OPD of Institute of Venereology, from March 1,2007 to February 29, 2008

\section{Method and Materials}

Specimens collected were 1)First catch 30ml of urine from both sexes,2)Endocervical swab from females, 3)Urethral swab from males.

\section{Results}

Prevalence of Gonococcal infections(Males -41, Females 36) was high compared to Chlamydia trachomatis infections (Males-10, Females -10) among 280 men and 270 women tested.

In gonococcal infections men (14.64\%), were more commonly infected than women (13.34\%). In Chlamydial infections females (3.70\%) were more commonly infected than males $(3.57 \%)$

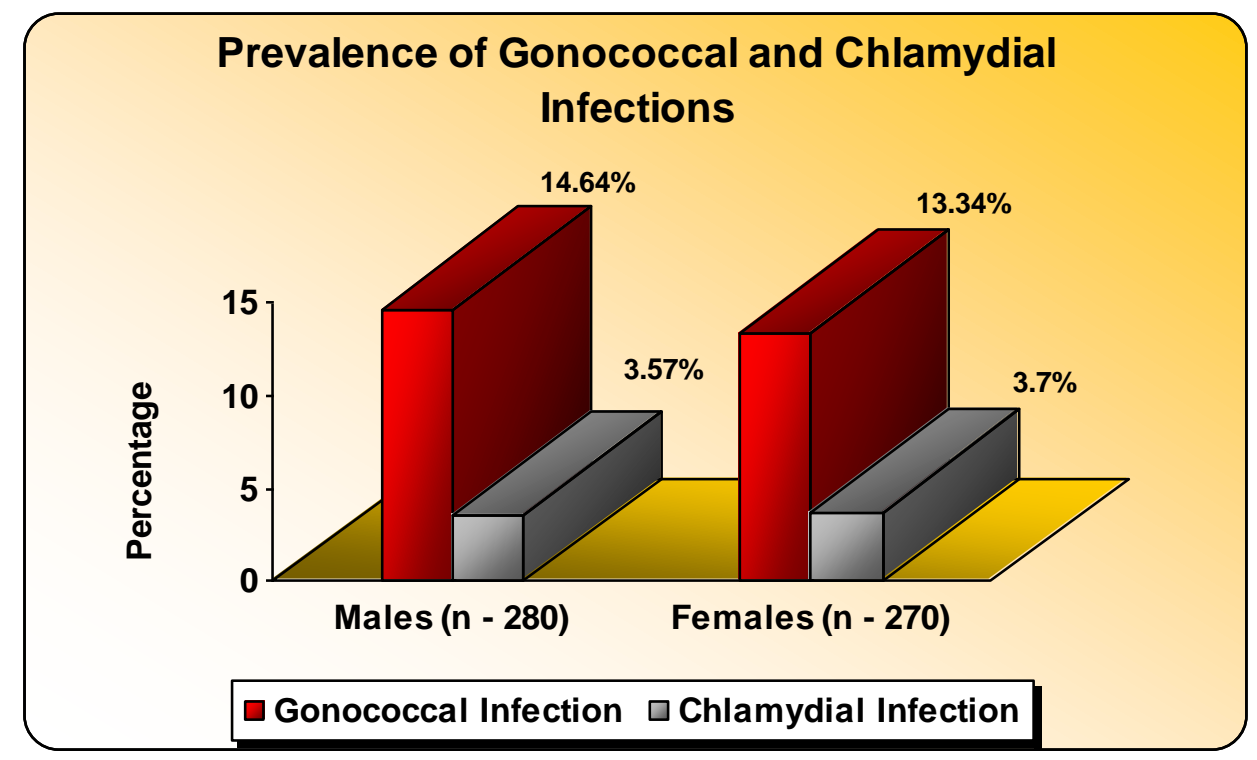




\section{International Journal of Science and Research (IJSR) \\ ISSN (Online): 2319-7064 \\ Index Copernicus Value (2013): 6.14 | Impact Factor (2015): 6.391}

Table 1: Number of positivity in urine and urethral swab specimens of affected males

\begin{tabular}{|c|c|c|c|c|c|c|c|c|}
\hline $\begin{array}{c}\text { Neisseria gonorrhoea } \\
\text { Infections } \\
\text { n-41 }\end{array}$ & \multicolumn{3}{|c|}{$\begin{array}{c}\text { Chlamydia trachomatis infections } \\
\text { n-10 }\end{array}$} & \multicolumn{3}{c|}{$\begin{array}{c}\text { Both NG and CT } \\
\text { n-4 }\end{array}$} \\
\hline Urine & Swab & Both & Urine & Swab & Both & Urine & Swab & Both \\
\hline 16 & 13 & 12 & 7 & 2 & 1 & 3 & - & 1 \\
\hline
\end{tabular}

In Gonococcal and Chlamydial infections, urine specimens showed more positivity than urethral swab specimens.

Table 2: Number of positivity in urine and endocervical swab specimens of affected females

\begin{tabular}{|c|c|c|c|c|c|c|c|c|}
\hline $\begin{array}{c}\text { Neisseria gonorrhoea } \\
\text { infections } \\
\text { n-36 }\end{array}$ & $\begin{array}{c}\text { Chlamydia trachomatis } \\
\text { infections } \\
\text { n-10 }\end{array}$ & \multicolumn{3}{c|}{ Both NG and CT } \\
\hline Urine & Swab & Both & Urine & Swab & Both & Urine & Swab & Both \\
\hline 15 & 13 & 8 & 3 & 6 & 1 & 2 & 5 & - \\
\hline
\end{tabular}

In Gonococcal infections urine specimens showed more positivity than endocervical swab specimens. In Chlamydial infections \& concomitant infections of both CT and NG, endocervical swab specimens showed more positivity than urine specimens.

Majority of both sexes belonged to 20-29 years age Male NG (43.90\%) and CT (50\%). Females NG(47.23\%) and CT $(60 \%)$

Majority of affected Males(NG-82.92\%, CT-90\%). and Females (NG-77.78\%,CT-80\%) belonged to lower socioeconomic status
Majority of affected both males(NG-46.34\%, CT-40\%) and Females (NG-47.23\%, CT-30\%) had High School education

Majority of affected males in the study group were married (NG-53.65\%, CT-70\%). Majority of affected females in the study group were married (NG-83.34\%, CT-80\%).

Burning micturition was the main complaint in affected males (NG-53.65\%, CT-80\%) followed by genital discharge (NG-21.95\%,CT -20\%) and genital ulcer (NG-7.31\%, CT30\%).(Fig 1.)

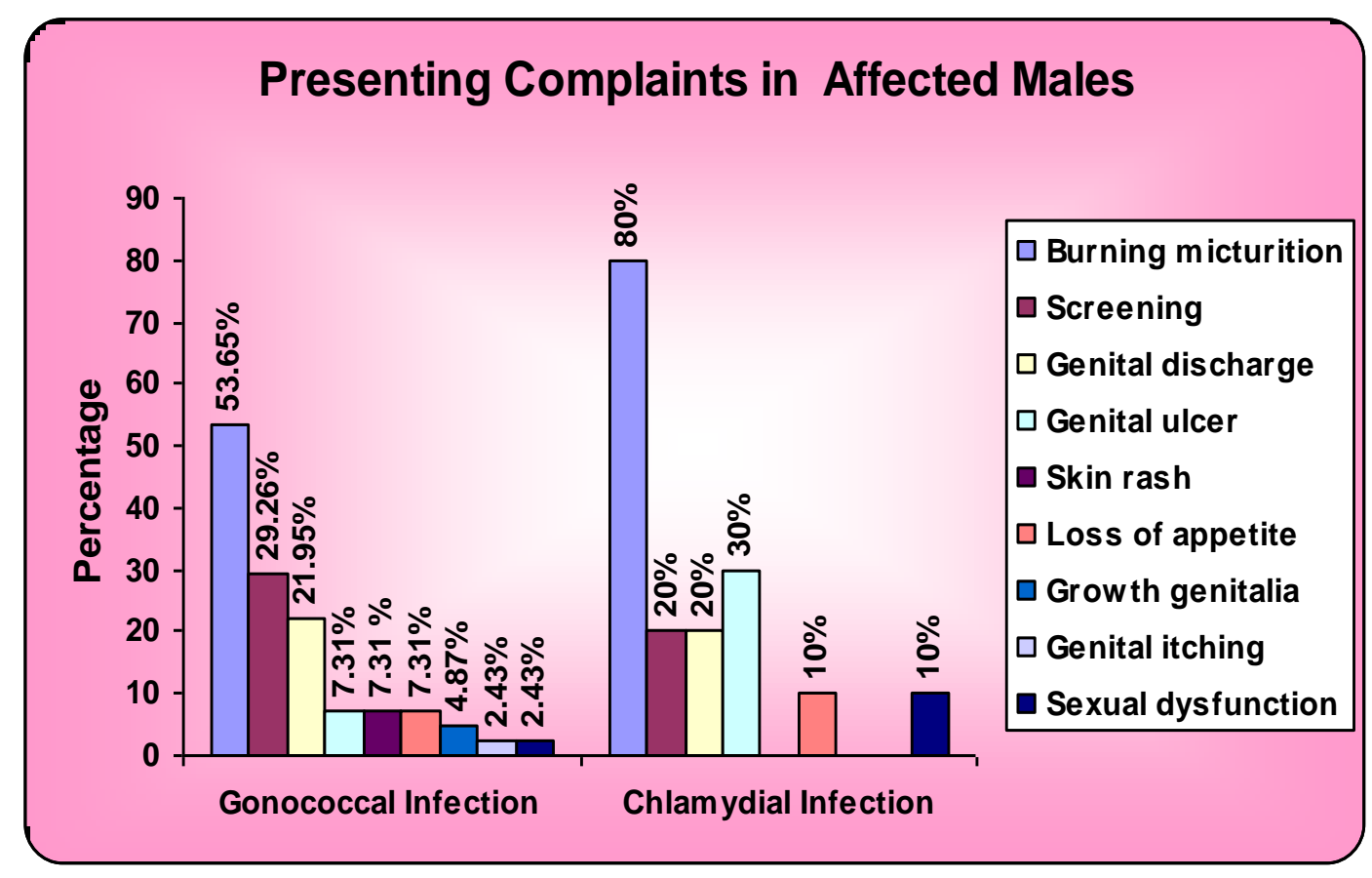

Figure 1

$29.26 \%$ of gonococcal infection positive males and 20\% of chlamydia trachomatis infection positive males came for screening.

Majority of the affected females visited for Genital discharge (NG-50\%, CT-50\%) followed by burning micturition (NG $-19.45 \%$, CT- $40 \%$ ).. $40 \%$ of chlamydial infection positive patients and $27.78 \%$ of gonorrhoeae positive patients came for screening.
In gonorrhoeae positive males urethral discharge (14.63\%) was the most common clinical sign followed by genital ulcer $(9.75 \%)$ and genital wart (7.31)\%.

In Chlamydia trachomatis infection positive males genital ulcer (30\%) was the most common clinical sign followed by urethral discharge (10\%), genital wart (10\%). 


\section{International Journal of Science and Research (IJSR) \\ ISSN (Online): 2319-7064 \\ Index Copernicus Value (2013): 6.14 | Impact Factor (2015): 6.391}

In gonococcal infection positive female patients, 58.34\% had cervical erosions, followed by cervical hypertrophy (16.67\%), soddening of vulva (11.12\%), $25 \%$ of them had healthy cervix. In Chlamydial infection positive females also, cervical erosion (70\%) was the most common clinical sign followed by cervical hypertrophy (10\%), soddening of vulva (10\%), genital wart (10\%), Bartholin cyst (10\%) and 20\% had healthy cervix(Fig.2)

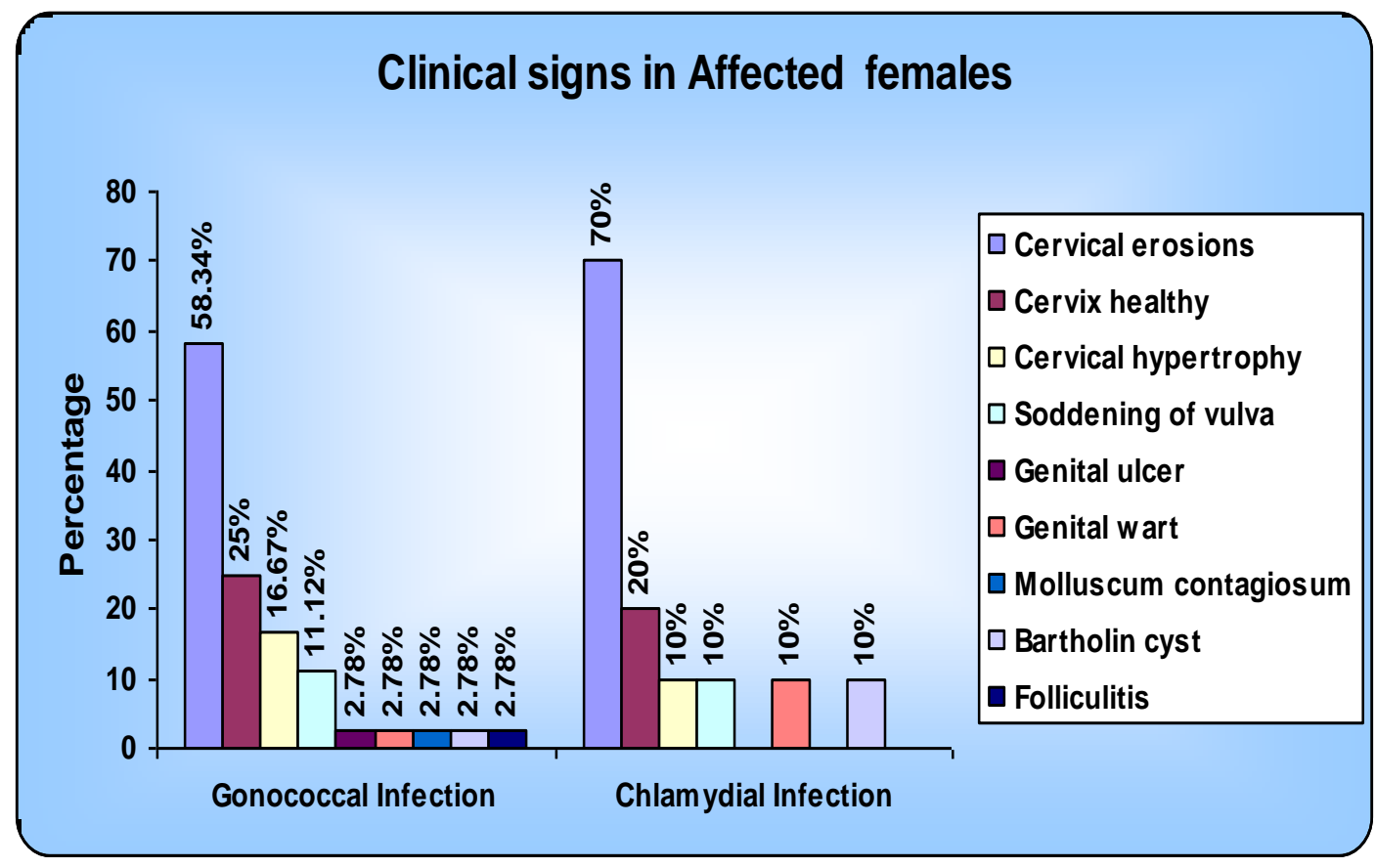

Figure 2

Majority of the affected women had mucopurulent vaginal discharge (NG-50\%, CT-40\%).

\section{Discussion}

During the study period, 550 patients were enrolled for Multiplex Amplicor CT/NG PCR study. Out of 550 patients 280 were males and 270 were females.

$14.64 \%$ of males and $13.34 \%$ of females were positive for gonococcal infection. $3.57 \%$ of males and $3.70 \%$ of females were positive for Chlamydial infections. This was comparable with the study done by William $\mathrm{C}$ et al in which $3.67 \%$ males and $4.74 \%$ of females were positive for $\mathrm{C}$. trachomatis infections.

Gonococcal infections (males $-14.64 \%$, females $-13.34 \%$ ) were more common than Chlamydial infections (males $3.57 \%$ females $3.70 \%)$.

In gonococcal infections men(14.64\%), were more commonly infected than women (13.34\%). In Chlamydial infections females (3.70\%) were more commonly infected than males (3.57\%). This result correlates with William C et al study in which $4.74 \%$ of females were positive for Chlamydial infection compared to males of $3.67 \%$.

In Urine PCR (m-16,f-15)showed more positivity than male urethral (13)and female endocervical swab PCR(13) in gonococcal infection positive patients. In Chlamydial infection positive males urine PCR(7) showed more positivity than urethral swab $\operatorname{PCR}(2)$, but in females endocervical swab PCR(6) showed more positivity than urine PCR(3).

Asymptomatic gonococcal infection was common in affected males (29.26\%) when compared to affected females (27.78\%). Asymptomatic Chlamydial infection was common in affected females (40\%) than affected males (20\%).

In gonococcal infection positive males, AMPLICOR CT/NG PCR had sensitivity, specificity, positive predictive value and negative predictive value of $100 \%$, 92\%, $46 \%$ and $100 \%$ respectively. In gonococcal infection positive females, AMPLICOR CT/NG PCR had sensitivity, specificity, positive predictive value and negative predictive value of $100 \%, 92 \%, 44 \%$ and $100 \%$ respectively.

In Chlamydia trachomatis infection positive males, AMPLICOR CT /NG PCR had sensitivity, specificity, positive predictive value and negative predictive value of $100 \%$, 99\%, $70 \%$ ad $100 \%$ respectively. In C. trachomatis infection positive females, the sensitivity, specificity, positive predictive value, and negative predictive value of AMPLICOR CT/NG PCR were 100\%, 98\%, 50\% and 100\% respectively.

Majority of Gonococcal (43.90\%) and Chlamydial (50\%) infection positive males belonged to 20-29 years age group, similarly in affected females majority belonged to 20-29 years age group (NG-47.23\%, CT- 60\%) which was similar to many studies ${ }^{2-6}$ in India and worldwide. Majority of affected males belonged to lower socioeconomic status (NG82.92\%,CT-90\%). In affected females also, majority 


\section{International Journal of Science and Research (IJSR) \\ ISSN (Online): 2319-7064 \\ Index Copernicus Value (2013): 6.14 | Impact Factor (2015): 6.391}

belonged to lower socioeconomic status (NG-77.78\%, CT$80 \%)^{7-9}$

Majority of affected males had high school education (NG$46.34 \%$, CT-40\%) ${ }^{10}$. Similarly, majority of affected females had high school education (NG-47.23\%, CT-30\%). 53.65\% of gonococcal and $70 \%$ of Chlamydial infection affected males were married. Majority of the affected females in the study group were married (NG-83.34\%, CT-80\%).

Burning micturition was the main complaint in affected males (NG-53.65\%,CT-80\%) followed by genital discharge (NG-21.95\%, CT-20\%)

\section{Conclusion}

Gonococcal infections (males -14.64\%, females -13.34\%) was more common than Chlamydia trachomatis (males$3.57 \%$, females $-3.70 \%$ ) infections. Gonococcal infection was more common in men (14.64\%) compared to women (13.34\%). Chlamydial infection was more common in women (3.70\%) when compared to men (3.57\%).

AMPLICOR CT /NG PCR for urine specimens (M-16, F15) was highly sensitive than male urethral (13) and female endocervical swab (13) specimens in detecting gonococcal infections. In Chlamydial infections, urine PCR (7) was highly sensitive than urethral swab PCR (2) in males but in females, endocervical swab PCR(6) was more sensitive than urine PCR (3).

Asymptomatic gonococcal infection was common in affected males (29.26\%) when compared to affected females (27.78\%). Asymptomatic Chalmydial infection was common in affected females (40\%) compared to affected males (20\%)

In Chlamydial infection positive patients, gonococcal infection was the most commonest associated STI (M-30\%, F-70\%). In gonococcal infection positive males, $\mathrm{C}$. trachomatis (7.31\%) was the commonest associated STI and in females, Bacterial vaginosis (41.67\%) was the commonest associated STI.

AMPLICOR CT/NG PCR had 100\% sensitivity in detecting gonococcal and chlamydial infections. PCR screening will diagnose asymptomatic cases of both gonococcal and chlamydial infections.

\section{References}

[1] Jossens MOR,Schachter J, Sweet RL, Risk factors associated with pelvic inflammatory disease of differing microbial etiologies. Obstet Gyanaecology 1994; 83: 989 - 97

[2] Chopra A, et al. Pattern and Changing trend of STDs at Patiala. Indian J. Sex. Transm Dis. 1999; 20: 22-25.

[3] Khandpur S, Agarwal S, Kumar S, et al. Clinico epidemiological profile and HIV Seropositivity of STD patients. Indian J. Sex Transm Dis 2001: 22: 62-65.

[4] Judson FN. Gonorrhoeae. Med Clin North AM 1990: 74: $1353-67$.
[5] Gastrin B, et al. Improved methods for gonococcal sampling and examination. Act a Pathol. MicrobiolScand 1968: 74: 362: 370.

[6] Morse SA, et al: In Topley and Wilson's systemic Bacteriology, Microbiology and Microbial Infections Vol. 2 (Balows A, et al.Eds) $9^{\text {th }}$ ed. London, Edward Arnold 1998: 877-900.

[7] Jaiswal AK, Bhushan B. Pattern of Sexually Transmitted Diseases in North Eastern India. Indian J Sex Transm Dis 1994;15: 19-20

[8] Parmar J, Raval RC, Bilimoria FE. Clinical Profile of STD's at Civil Hospital Ahmedabad Indian J Sex Transm Dis 2001;22: 14-16

[9] Ranganyakulu B, Ravikumar GP , Bhaskar GV, Pattern of STD's at Karnool Indian J Sex Transm Dis 1998; 19: 117-21

[10] Gupta SK , Jain VK, Pattern of Sexually Transmitted Diseases in Rohtak Indian J Sex Transm Dis 1995;16: 28-29 